\title{
Three new species of the genus Drymeia Meigen (Diptera: Muscidae) from the Qinghai-Xizang (Tibet) Plateau, China
}

\author{
Wan-Qi Xue*, Dan-Dan Wang \& Ming-Fu Wang
}

Xue, W. Q., Wang, D. D. \& Wang, M. F. 2009: Three new species of the genus Drymeia Meigen (Diptera: Muscidae) from the Qinghai-Xizang (Tibet) Plateau, China. - Entomol. Fennica 20: 84-93.

Three new species of Drymeia are described from Qinghai-Xizang (Tibet), China: Drymeia fimbricauda Xue, sp. n., Drymeia katepimeronipilosa Xue, sp. n. and Drymeia quadratimacula Xue, sp. n. The type specimens of the new species are deposited in the Institute of Entomology, Shenyang Normal University. In addition, a generic diagnosis of Drymeia is given, and five species assigned to the genus Drymeia Meigen in Flies of China are transferred to the genus of Spilogona Schnabl. In the genus Drymeia, 48 species are now known from China. The effects of the uplift of the Qinghai-Xizang (Tibet) Plateau on the structural diversity of Drymeia species are discussed.

W.-Q.Xue*, D.-D. Wang \& M.-F. Wang, Institute of Entomology, Shenyang Normal University, Shenyang 110034, China; * E-mail of the corresponding author: xwqfly@sina.com

Received 14 July 2007, accepted 18 January 2008

\section{Introduction}

Drymeia Meigen is a genus of the family Muscidae and was described by Meigen in 1826, with Drymeia obscura as the type species. Over the next century, a number of additional related genera were described, but Pont (1986) synonymised all of these with the genus Drymeia Meigen: Eriphia Meigen, 1826; Bebryx Gistl, 1848; Pogonomyia Rondani, 1871; Neoeriphia Schnabl and Dziedzacki, 1911; Neopogonomyia Schnabl and Dziedzicki, 1911; Trichopticoides Ringdahl, 1931. Although they are very similar in larval morphology, the main differences between these taxa reflected the adult habits and morphology, particularly in the development of the head and proboscis and in the thoracic chaetotaxy.

The regional Diptera catalogues and other major works have summarised knowledge of the genus Drymeia that has been built up during the century-and-a-half since the time of Meigen. Huckett (1965a, 1965b) has dealt with the Nearctic species, so that 13 species are now known from that region. Hennig (1962) revised the $\mathrm{Pa}-$ laearctic species, which were subsequently catalogued by Pont (1986), and 27 species were recorded in those papers. Xue and Zhang (1996a, 1996b) and Xue and Chao (1998) recorded 40 species of Drymeia from China (including the five species that are transferred later in this paper to the genus Spilogona Schnabl), giving a new total of 64 species for the Palaearctic region. There are a few Oriental species (Pont 1977, 1981, Shinonaga \& Singh 1994) and a Neotropical one (Carvalho et al. 2002). No species of Drymeia are known from the Afrotropical (Pont 1980) or Australasian (Pont 1989) regions. The genus currently contains 67 species. 
Genus Drymeia Meigen, 1826

Drymeia Meigen, 1826: 204. Type-species: Drymeia obscura Meigen, 1826: 204 (= Musca hamata Fallén, 1823), by monotypy.

The generic synonyms of Drymeia Meigen are listed in Pont (1986).

Generic diagnosis. Haustellum of proboscis long and thin; anterior margin of gena always swollen, with many subvibrissal setulae; parafacial always wide, at least equal to the 1st flagellomere in width; arista pubescent; frontal setae long and dense; Sc and M veins always straight; legs entirely black; hind tibia and 1st tarsomere on fore leg always with an apical ventral projection; ventral surfaces of fore and mid tibiae always with setae; middle of hind tibia always with $2-3 p d$, each seta at least 1.5 times as long as diameter of tibia; hind coxa bare on posterior surface; abdomen without paired spots; cerci emarginate apically.

Distribution. Drymeia is a typical Holarctic genus. Most species are found at high altitude or at high latitude, and the genus is especially speciose in Palaearctic Central Asia, in Mongolia and the Qinghai-Xizang (Tibet) province of China.

\section{Material and methods}

The morphological terminology follows that of McAlpine (1981). Absolute measurements are used for body length in millimetres ( $\mathrm{mm}$ ). Abbreviations used in this study include the following. Wing: Sc: subcostal vein; R1, R4+5, R5: branches of radius vein; $\mathrm{M}$ : media vein; $\mathrm{M} 1+2$ : branch of media vein. Setae: pra: prealar seta; $a c r$ : acrostichal seta; $d c$ : dorsocentral seta; $v$ : ventral seta; $a v$ : anteroventral seta; $a d$ : anterodorsal seta; $p d$ : posterodorsal seta; $p$ : posterior seta; $p v$ : posteroventral seta.

The material studied here, including holotypes of the new species, is in the Institute of Entomology, Shenyang Normal University, Shenyang 110034, Liaoning Province, P.R. China.

\section{Taxonomy}

\subsection{Five species of Drymeia transferred into Spilogona}

Five species described into the genus Drymeia by Xue et al. (1992) are here transferred into the genus Spilogona Schnabl. They lack the characters of Drymeia, such as: In the more basal groups (Azeliini, Muscini, Atherigoninae, Phaoniinae) the cerci are rather long and project tube-like beyond the tip of the ovipositor; In the more apical groups (Mydaeinae, Limnophorini, Coenosiini) the cerci are shorter, do not project, and are pressed against the membranes around the epiproct and hypoproct (apical tergite and sternite, and the full development of sternite 8 as a pair of long rods in the Azeliini and Muscini, whereas this sternite is reduced to two small hind-marginal platelets in the Limnophorini and Coenosiini; emarginated part of male cerci short and blunt; posterior margin of male surstyli always with a process; the prealar seta absent; middle of hind tibia always with $2-3 p d$, their length at least 1.5 times as long as diameter of the tibia; hind tibia and 1st tarsomere of fore tarsus always with an apical ventral projection; abdomen generally without paired spots. Spilogona species generally have hind tibia without $p d$, but if a short seta is present then abdominal tergites 3 and 4 have paired black spots; Spilogona also rarely has the setae on the ventral surfaces of fore and mid tibiae that are characteristic of Drymeia. The 5 species transferred to the genus Spilogona Schnabl are listed below.

1. Spilogona leptostylata (Xue and Xiang in Xue and Chao, 1998: 871), comb. n.

Type-locality: Kaerdong, Dongkunlun, Xinjiang, China.

Distribution: Xinjiang, China.

2. Spilogona leuciscipennis (Xue and Xiang in Xue and Chao, 1998: 872), comb. n.

Type-locality: Kaerdong, Dongkunlun, Xinjiang, China.

Distribution: Xinjiang, China.

3. Spilogona lolliguncula (Xue and Xiang in Xue and Chao, 1998: 872), comb. n. 

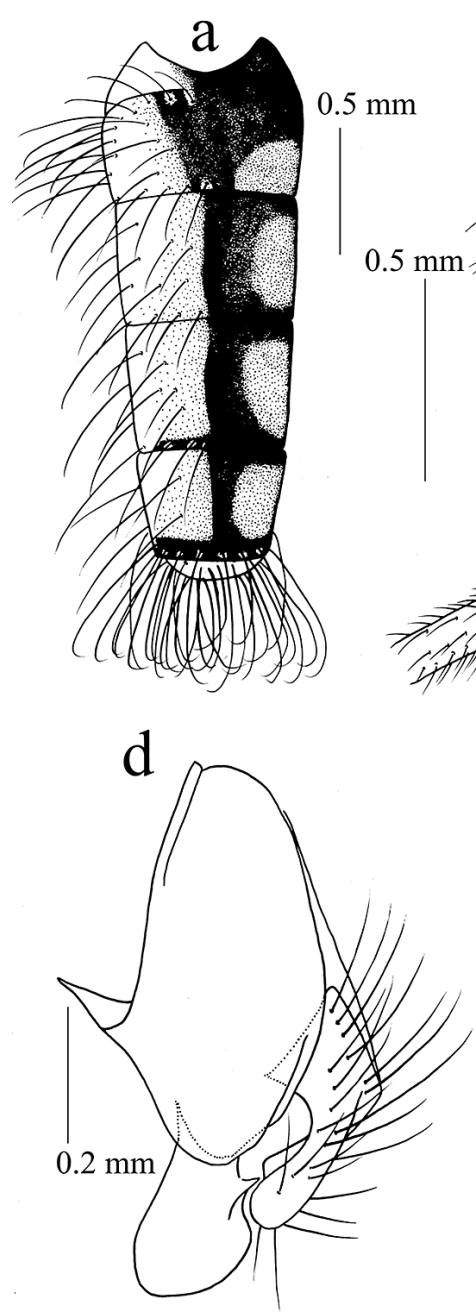

b
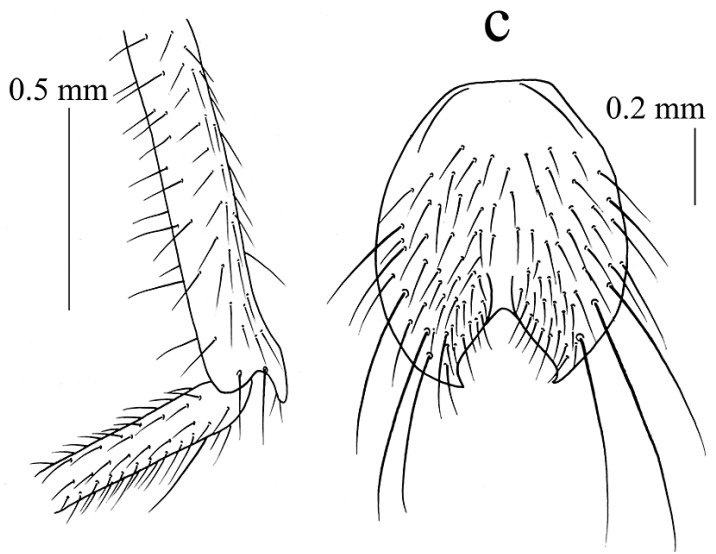

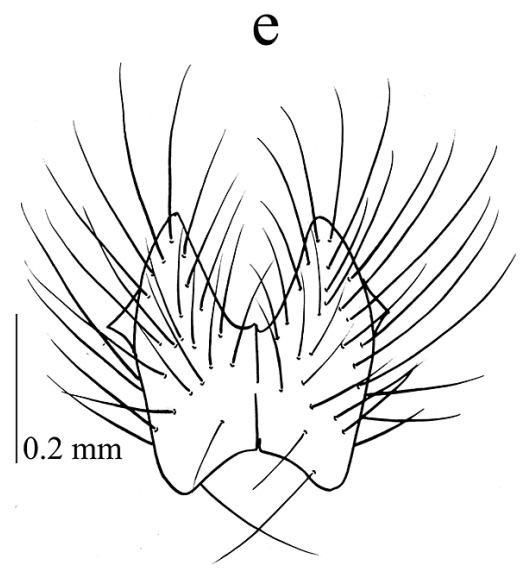

Fig. 1. Drymeia fimbricauda Xue, sp. n. (male). - a. Abdomen in dorsal view. $-b$. Hind tibia in anterior view. -c. Sternite 5 in ventral view. - d. Terminalia in profile. - e. Cerci in posterior view.

Type-locality: Hasa, Dongkunlun, Xinjiang, China.

Distribution: Xinjiang, China.

4. Spilogona quadrula (Xue and Xiang in Xue and Chao, 1998: 874), comb. n.

Type-locality: Tufangzi Dongkunlun, Xinjiang, China.

Distribution: Xinjiang, China.

5. Spilogona spinisurstyla (Xue and Xiang in Xue and Chao, 1998: 874), comb. n.

Type-locality: Tufangzi, Dongkunlun, Xinjiang, China.

Distribution: Xinjiang, China.

\subsection{Description of three new species}

A key of males of Chinese Drymeia was presented by Xue et al. (2007). In connection of the description of each new species, we point in the remarks the most closely resembling other species of Drymeia. Accordingly, the new species will appear in the key by Xue et al. (2007) in connection of these closest species.

\subsubsection{Drymeia fimbricauda Xue, sp. n. (Fig. 1)}

Type material. Holotype: male, P.R. CHINA: Yunnan, Baimang Snowberg, 4,300 m a.s.1., 4.VII.2006 (Ming-fu Wang). In the Institute of Entomology, Shenyang Normal University, Shenyang, Liaoning Province, P.R.China. 
Paratypes: 19 ठึग, P.R. CHINA: Yunnan, Baimang Snowberg, 4,300 m a.s.1., 4.VII.2006 (Ming-fu Wang); 3 ふึ่, P.R. CHINA: Yunnan, Baimang Snowberg, 4,300 m a.s.1., 4.VII.2006 (Liang Chang); 12 ふึ$\hat{\jmath}$, P.R. CHINA: Yunnan, Baimang Xueshan, 4,300 m a.s.1., 4.VII.2006

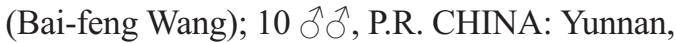
Baimang Snowberg, 4,300 m a.s.1., 4.VII.2006 (You Wang).

Description. Male. Body length 6.5-7.0 mm.

Head: Head spherical. Eye bare; frons about 0.3 times as wide as head width; frontal vitta black, about 2.5 times as wide as fronto-orbital plate; 4-5 frontal setae, 3 orbital setae; ocellar setae equal to the longest frontal seta; parafacial with black pruinosity, equal to $1 \mathrm{st}$ flagellomere in width; antennae black, 1st flagellomere about 1.8-2.0 times as long as wide; arista pubescent, the longest aristal hairs shorter than its basal diameter; facial carina indistinct; epistoma and frontal angle in one perpendicular line; upper part of vibrissal angle with 3 setae; gena black, without upcurved peristomal bristles; genal height about $1 / 5$ of eye height; beard and postgena setae all black; dorsal part of occiput with hairs; proboscis thin and long, prementum with a little grey pruinosity, about 4.5 times as long as wide; palpi black, about 3/4 length of prementum.

Thorax. Ground-colour black, with a little brownish-grey pruinosity; scutum with four distinct vittae, inner vittae not reaching scutoscutellar suture; with 2 irregular rows of presutural acr, 1 postsutural acr, dc 2+3, ia $0+2$, pra about 1.3 times as long as posterior notopleural seta; notopleuron bare (a few with hairs); lateral and ventral margins of scutellum, basisternum of prosternum, anepimeron, meron and katepimeron all bare; katepisternal setae $1+1$; spiracles small and blackish-brown.

Wing. Colour hazel, wing base and veins brown; basicosta black; costal spine short; Sc straight; R4+5 and M parallel, more or less separated distally; veins bare except fore margin of $\mathrm{C}$ with setulae; upper calypter yellow to brown, lower calypter projecting, tongue-shaped, brown to dust coloured, margin dark; halteres black.

Legs. Entirely black; fore tibia with $2-3 p v$ at middle; mid femur always slightly curved, with a complete $a v$ row, becoming longer towards apex, in front of it with another $a v$ row at middle of ven- tral surface (about 5-6), with a complete and thin $p v$ row, becoming shorter towards apex; mid tibia with many rows of fine and long hairs, $3 \mathrm{ad}, 4 \mathrm{pd}$, with a long hair-like $p v$ row, most setae about 2.53.0 times as long as the tibial diameter; hind femur with a complete row of $a v$, hair-like in basal half, 2 irregular rows of $p$ in basal 1/3-2/5, without $p v$; hind tibial hairs fine and short, with 4-5 fine hair-like $a v, 4-5 p d$ at middle, their length about 3.5 times as long as tibial diameter; the apical ventral projection angular, with 2 short setae and a tiny sensory hair on it; claws and pulvilli small, shorter than 5th tarsomere.

Abdomen. Black, elongate barrel-shaped, with a little brownish-grey pruinosity, black median vitta indistinct; posterior margin of tergite 5 and surface of tergite 9 with long fringes; sternite 1 with hairs, sternite 2 with long and strong setae; lateral lobe of sternite 5 directed ventrally, with 3-4 long fringes; processes on inner margin of surstylus pointed at middle in profile.

Female: Unknown.

Remarks. This new species resembles Drymeia aculeata (Stein, 1907), but it differs from the latter in having the male frons wider, about 0.3 times as wide as head width; hind tibial hairs fine and short, with 4-5 fine hair-like $a v, 4-5 p d$ in a row in the middle, about 3.5 times as long as tibial diameter, without ad.

Etymology. The species name is from the Latin fimbriae (= "fringe") and cauda (= "tail"), and refers to the long fringes at the posterior margin of tergite 5 and on the surface of tergite 9 in the male.

\subsubsection{Drymeia katepimeronipilosa Xue, sp. n.}

(Fig. 2)

Type material. Holotype: male, P.R. CHINA: Sichuan, Luhuo, 4,300 m a.s.1., 16.VIII.2006 (Dan-dan Wang). Paratypes: 3 $\widehat{\delta}$ and 8 우, with the same data as holotype.

Description. Male. Body length 6.5-7.0 mm.

Head: Eye bare; frons about 1.0-1.5 times as wide as anterior ocellus; frontal vitta black, becoming obsolete in middle; $13-14$ frontal setae, reaching to the two sides of anterior ocellus, without orbital setae; fronto-orbital plate with grey pruinosity; parafacial with silvery-white pruinosity, about $1.5-1.7$ times as wide as 1st flagello- 

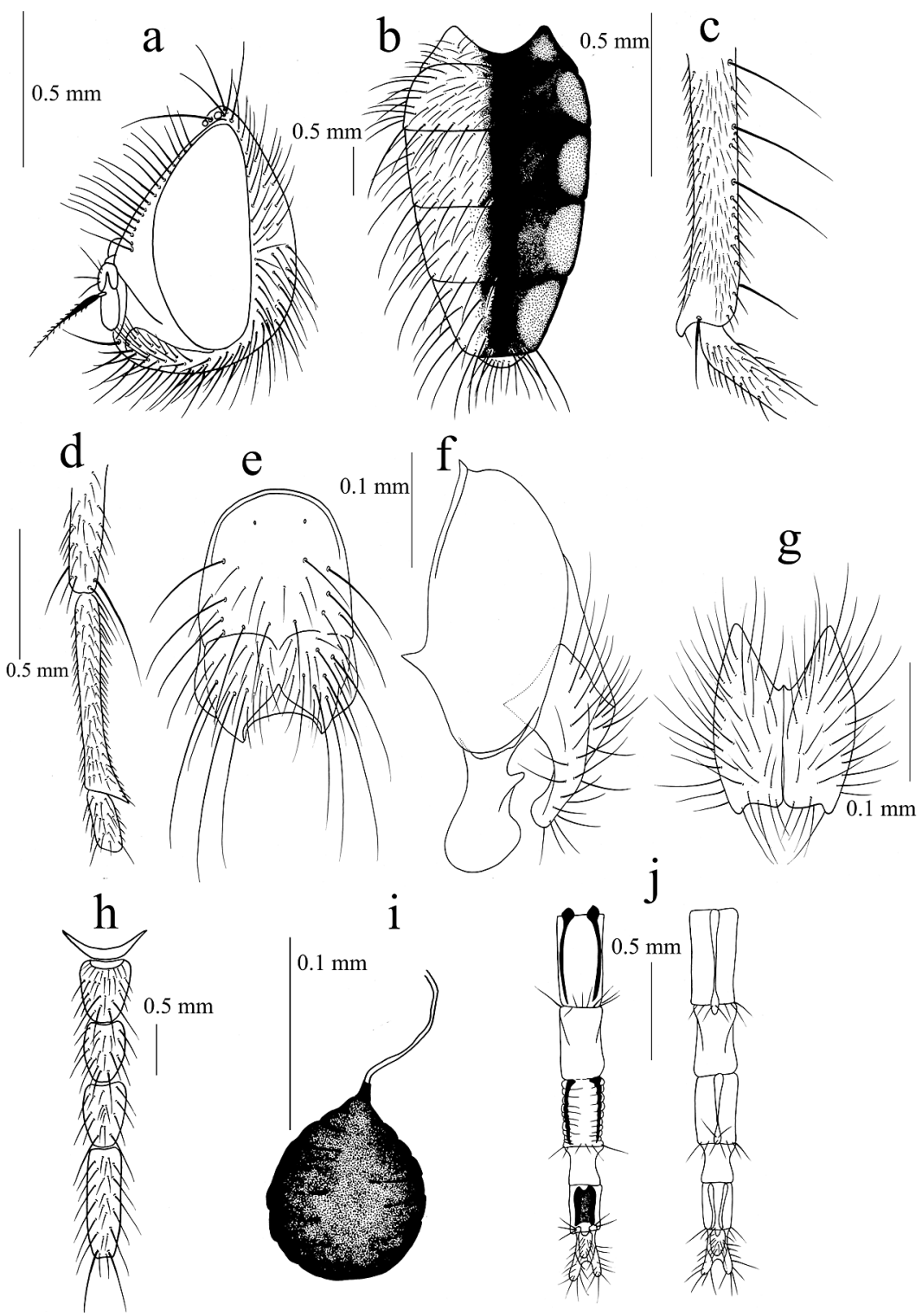

Fig 2. Drymeia katepimeronipilosa Xue, sp. n. (male and female). : $:-a$. Head in profile. $-b$. Abdomen in dorsal view. - c. Hind tibia, apical part in posterior view. - d. 1 st tarsomere of fore tarsus in posterior view. - e. Sternite 5 in ventral view. $-f$. Terminalia in profile. $-g$. Cerci in posterior view. o: - h. Sternites 1-5. - i. Spermatheca. $-\mathrm{j}$. Ovipositor in ventral and dorsal views.

mere; antennae black, 1st flagellomere about 1.5 times as long as wide; arista pubescent; facial carina developed, occupying the width of lunula and projecting over anterior margin of frons in profile; epistoma projecting in profile; vibrissal angle situated in front of frontal angle in profile; gena black, with 4-5 rows of upcurved peristomal bristles; genal dilation enlarged and extending to base of vibrissal angle; genal height about $1 / 7$ of eye height; beard and postgenal setae all black; dorsal part of occiput with hairs; proboscis thin and long, prementum with a little grey pruinosity, about 7.0 times as long as broad; palpi black, about $1 / 2$ length of prementum.

Thorax. Ground-colour black, scutum with a little bluish-grey pruinosity and four vittae; with 4 irregular rows of presutural $a c r, 1$ postsutural $a c r, d c 2+3$, ia $0+2$, pra about 1.2 times as long as posterior notopleural seta; notopleuron and katepimeron with hairs, lateral and ventral margins of scutellum, basisternum of prosternum, anepimeron and meron all bare; katepisternal setae 1+2(3); spiracles small, blackish-brown.

Wing. Colour hazel, both wing base and veins 
brown; basicosta black; costal spine short; Sc straight; R4+5 and M parallel, more or less separated distally; veins bare except for front edge of $\mathrm{C}$ with setulae; calypters brownish-yellow; halteres black.

Legs. Entirely black; fore tibia with $3 p v$ at middle; fore 1st tarsomere with a cone-shaped process on ventral surface; mid femur with a complete $a v$ row, in the middle the setae thick and long, and a complete and fine $p v$ row; mid tibia with 3-5 ad, 4-5 $p d, 3-4 p v$; hind femur with a complete row of $a v$, without $p v$; hind tibia with 4 short $a v, 2-3 a d, 4-5 p d$, without $p v$; apical ventral projection short and small, with a tiny sensory hair and 2 short setulae; all tarsi about equal to tibiae in length, 4th tarsomere indistinct.

Abdomen. Black, short cone-shaped, with a little brownish-grey pruinosity and olive-green metallic lustre; lateral setae and posterior marginal setae long and large; tergite 3 with a wide black median vitta, but tergites 4-5 with a narrow black median vitta; sternite 1 bare, sternite 2 with long and large setae; processes on inner margin of surstylus finger-shaped at middle in profile.

Female. Body length 6.5-7.0 mm. Frons about 0.4 times as wide as head width; with a pair of interfrontal setae; frontal vitta about 2.2-2.5 times as wide as fronto-orbital plate; 5 frontal setae, 3 pairs of orbital setae, 2 outer vertical setae; genal height about $1 / 6$ of eye height; with 2 rows of upcurved peristomal bristles; wing brown; mid femur with a short $a v$ row; mid tibia with $2 a v$; hind tibia with $4 a d$, without apical ventral projection; tergite 3 with a narrow black median vitta, which is wider than $1 / 2$ length of the tergite; 3 spermathecae; tergite 8 in the form of a tile; other characters as in male.

Remarks. This new species resembles Drymeia palpibrevis (Fan, Jin and $\mathrm{Wu}, 1988$ ), but it differs from the latter in that the anterior margin of gena in the male has 4-5 rows of upcurved peristomal bristles; katepimeron with hairs; fore tibia with $3 p v$ at middle, fore 1 st tarsomere with a cone-shaped process on ventral surface, not exceeding $1 / 2$ length of the 2 nd tarsomere.

Etymology. The species name is from the morphological term katepimeron and the Latin pilosus (= "hairy") and refers to the haired katepimeron.

\subsubsection{Drymeia quadratimacula Xue, sp. n.} (Fig. 3)

Type material. Holotype: male, P.R. CHINA: Yunnan, Shangri-La, 3,700 m a.s.1., 2.VII.2006 (Bai-feng Wang). Paratypes: 9 우, P.R. CHINA: Yunnan, Shangri-La, 3,700 m a.s.1., 2.VII.2006 (Liang Chang); $11 \hat{\jmath} \hat{\jmath}$, P.R. CHINA: Yunnan, Shangri-La, 3,700 m a.s.1., 2.VII.2006 (You Wang); 3 $\hat{\jmath}$, with the same data as holotype.

Description. Male. Body length 5.5-6.0 mm.

Head: Eye bare; frons slightly narrower than the distance between outer margins of posterior ocelli; frontal vitta black, narrower than the width of one fronto-orbital plate; 8-9 frontal setae, the upper one always directed backwards; ocellar setae longer than the longest frontal seta; without orbital setae; fronto-orbital plate with dark grey pruinosity; parafacial with silvery-grey pruinosity, about1.2-1.4 times as wide as 1st flagellomere; antennae black, 1 st flagellomere about 1.52.0 times as long as wide; arista pubescent, the longest aristal hairs shorter than its basal diameter; facial carina developed, projecting over half width of pedicel; epistoma distinctly projecting, vibrissal angle situated in front of frontal angle in profile; gena black, genal dilation extending to base of vibrissal angle, with 3-4 rows of upcurved peristomal bristles; genal height about $1 / 5$ of eye height; beard and postgenal setae all black; dorsal part of occiput with hairs; proboscis thin and long, prementum with a little grey pruinosity, about 5.0 times as long as broad; palpi black, about $3 / 4$ length of prementum.

Thorax. Ground-colour black, with grey pruinosity; scutum with four distinct vittae, the inner ones not reaching scutoscutellar suture; with 2 irregular rows of presutural acr, 1 postsutural acr, $d c 2+3$, ia $0+2$, pra about 1.3 times as long as posterior notopleural seta; notopleuron with hairs, lateral and ventral margins of scutellum, basisternum of prosternum, anepimeron, meron and katepimeron all bare; katepisternal setae $1+1$ (a few with $1+2$ ); spiracles small and brown.

Wing. Colour hazel, both wing base and veins brown; basicosta black; costal spine short, Sc straight; R4+5 and M parallel, more or less separated distally; veins bare except fore-margin of $\mathrm{C}$ with setulae; calypters yellow, lower calypter 


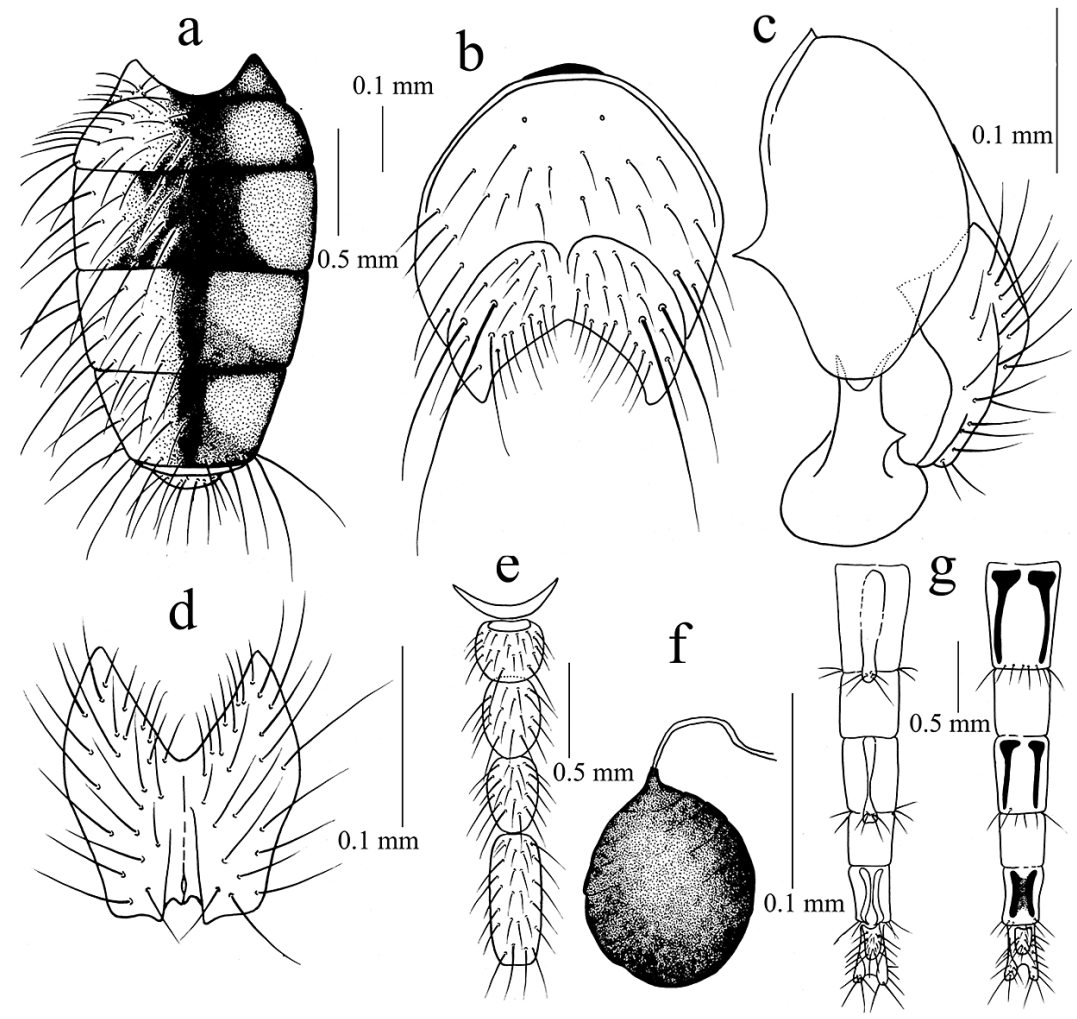

Fig 3. Drymeia quadratimacula Xue, sp. n. (male and female). o: - a. Abdomen in dorsal view. $-b$. Sternite 5 in ventral view. -c. Terminalia in profile. - d. Cerci in posterior view. O. - e. Sternites 1-5. - f. Spermatheca. - g. Ovipositor in ventral and dorsal views. projecting, tongue-shaped; halteres black.

Legs. Entirely black; fore tibia with $1 p v$ in the middle; mid femur with a distinct $a v$ row in apical half, becoming shorter towards apex, with a complete and fine $p v$ row; mid tibia with 1-2 $a v, 1 a d$, 2-3 $p d, 1-2 p v$; hind femur with a complete row of $a v$, without $p v$ except in apical part, with a row of long hairs on posterior surface of basal $3 / 5$ which are slightly continuous with apical $p v$; hind tibia with 3-5 av, 2-4 strong ad in the ad row, 3-5 $p d$, without distinct $p v$, without an apical ventral projection (slightly produced in a few individuals); all tarsi shorter than length of tibiae, 4th tarsomere short, about $3 / 5$ length of 5 th tarsomere.

Abdomen. Black, short-conical, with a little grey pruinosity and olive-green metallic lustre; black median vitta very wide, especially tergite 3 where it is more or less square-shaped, black median vitta on tergite 4 about 1/4-1/3 length of the tergite; sternite 1 bare; setae on lateral lobe of sternite 5 long and strong; processes on inner margin of surstylus short and pointed in the middle in profile.

Female. Body length 5.5-6.0 mm. Frons about 0.28 times as wide as head width; with a pair of interfrontal setae (a few specimens without); 3-4 frontal setae; ocellar triangle very short; with 1 posterior and 2 upper orbital setae; 3-4 rows of upcurved peristomal bristles; wing brown; mid femur with 4-5 av apically, without distinct $p v$; hind femur without distinct $p v$ apically; tip of abdomen slightly pointed; 3 spermathecae; ovipositor with tergite 8 slightly enlarged; other characters as in male.

Remarks. This new species resembles Drymeia melargentea (Fan, 1992), but the male differs from the latter by having 8-9 frontal setae, the upper one always directed backwards; ocellar setae longer than the longest frontal seta; without orbital setae; anterior margin of gena with 3-4 rows of upcurved peristomal bristles; proboscis thin and long, prementum with a little grey pruinosity, about 5.0 times as long as broad; palpi black, about 3/4 length of prementum; hind tibia with 3-5 av, 2-4 strong $a d$ in the $a d$ row, 3-5 pd, without distinct $p v$, apical ventral projection indistinct but slightly produced in some specimens.

Etymology. The species name is from the 
Latin words quadrum (= "square") and macula (= "spot"), and refers to the square-shaped black median vitta on tergite 3 .

\section{Discussion}

\subsection{Effect of the uplift of the Qinghai-Xizang (Tibet) on the diversity of Drymeia species}

Species of Drymeia are distributed mainly over the high altitude region, mostly between 2,000 and 5,600 metres above the sea level. In China, there are already 44 described species of Drymeia (Fan 1993), of which 40 occur on the QinghaiXizang (Tibet) Plateau. It is clear that Drymeia is mainly distributed right across the QinghaiXizang Plateau and the neighboring area (Zhong et al. 1981).

The Qinghai-Xizang Plateau experienced the global climatic changes of the Quaternary period, with its alternation of glacial and interglacial stages. As the Himalaya range was continuously rising, and as the climate gradually became cold with the onset of each glaciation, conditions forced some northern Drymeia species to move southwards, even as far as India, Nepal, Sikkim, and so on. Two species are currently known from Kashmir (fumipennis (Malloch), beelzebub (Pont), and six species from Nepal (atrifrontata (Pont), beetzebub (Pont), lamellitarsis (Pont), nigrifrons (Pont), tysoni (Pont), and makiharai Shinonaga), at altitudes up to $5,000 \mathrm{~m}$ above the sea level, and these species mark the southern limit of the genus Drymeia. With the retreat of the ice at the start of the interglacials and with temperatures gradually rising, the cold-resistant ancestors of these endemic species, originally from the north, either moved back northwards with the retreat of the ice or, unable to cross the barrier formed by the Himalaya mountains, remained in the south and settled at high altitudes in the southern Himalaya. Through a long process of isolation and adaptation, they gradually evolved into the endemic current species and still remain as specialists of high mountain environments.

The Qinghai-Xizang Plateau has been continuously rising and falling, with high mountains and deep valleys, and presents a harsh ecological environment and difficult conditions for life.
These conditions have restricted the distribution of Drymeia species so that each one has a very narrow range and each special environment has its own endemic species. It is rare for any species to have a wide distribution, and it is the main reason for the diversity of Drymeia species on the Qinghai-Xizang Plateau.

\subsection{Adaption of Drymeia species to various phenological types in the Qinghai-Xizang Plateau}

Almost all Drymeia species inhabit high mountains up to the nival zone. In order to adapt to the varied environments of the Qinghai-Xizang Plateau, the morphological characteristics of the ancestral species evolved to resist the harsh conditions of the environment. Body colour, mouthparts, hairs and bristles, body shape, legs, terminalia and habits all evolved in different ways.

\subsubsection{Black body}

Since the environment on the high plateau where Drymeia species live has such an extreme temperature regime, the temperature utilization rate is limited and the ultraviolet radiation intensity is high. Drymeia species therefore tend to have a very black body colour, including legs, wings, calypters, halteres, basicosta and abdomen without differently coloured spots, and in this way they can absorb more effectively the heat from solar radiation and at the same time reduce the danger of burning from the ultraviolet rays. It is clear that the development of such a black body colour is a protective character and an adaptation to high mountain environments.

\subsubsection{Mouthparts slender}

Most species of Drymeia have elongated and slender mouthparts, such as D. fulvinervula (Fan, Jin \& Wu1988) which has a long and thin proboscis, about 4.0 times as long as broad. The labella are always small, the mouth-edge projects forwards well beyond the level of profrons, and the parafacial is very broad. In the type-species of Drymeia, D. hamata (Fallén), the labella are long and narrow and the apical part of the proboscis is 
bent back in the form of a hook. With their elongated mouthparts, Drymeia species are able to creep in among the petals of many types of plants, to feed on nectar and pollen and to find protection from the strong wind.

\subsubsection{Specialized hairs and setae}

Adults of Drymeia are usually provided with many fine and dense setae, for example the anterior margin of the gena may have many rows of upcurved subvibrissal setulae, such as $D$. spinifemorata (Stein 1907) in which there are about 10 rows of them. These setae can keep the body warm as well as increase the body surface for the absorption of heat from the sun. In a small number of species, such as D. beelzebub (Pont 1981) and D. totipilosa (Fan 1988), the lateral margin of the head, the thorax and the abdomen are provided with long, expanded and flattened setae, which is a highly specialized character for maintaining body temperature as well as for absorbing heat from the sun. The flattened setae can also protect against wind and rain. Other species with long fringes of setae at the tip of the abdomen, such as D. fimbricauda sp. n. and D. cinerea (Meigen), may have acquired such adaptations for balance and directional flight when flying in strong winds.

\subsubsection{Body shape streamlined}

In order to reduce resistance during flight and to adapt to the strong winds of the plateau, tremendous changes have taken place in the body shape of Drymeia species, such as the triangular shape of the head in lateral view, with mouth area and epistoma projecting forwards, and the slender and streamlined body, as typified by $D$. fimbricauda, sp. n. Such a shape enables stability and direction to be maintained while flying.

\subsubsection{Most adult males with an apical ventral projection on hind tibia and on tarsomere of fore tarsus}

The apical ventral projection always terminates in a tiny sensory hair by means of which the fly can detect whether its body touches the ground or not. The apical ventral projection acts like a ful- crum in strong winds, like a walking stick. It is also employed in climbing, courtship, copulation, and in maintaining body stability.

\subsubsection{Genitalia specialized for functioning in high and cold environments}

In males of Drymeia species, the surstyli have a pointed and inwardly-directed process, and in severe weather conditions such as strong winds, this process can help the male to clasp the female when mating, thus ensuring the success of copulation. In females of the basal Muscidae, tergite 8 is present as a pair of elongated rods, but in the high altitude Drymeia species (but not all species of the genus) the paired rods of tergite 8 have fused to form a single plate. This functions to increase the tension and rigidity of the ovipositor, and enables Drymeia females to copulate and lay eggs under cold and windy conditions.

Acknowledgements. This study was supported by the National Nature Science Foundation of China (No.30270166) and the Foundation of Experimental Centre of Shenyang Normal University (No.SY200609). Special thanks are due to Dr. A.C. Pont (Oxford University Museum of Natural History, Oxford, UK) for comments on and improving the manuscript, and also to Liang Chang, Bai-feng Wang and You Wang (Shenyang Normal University, Liaoning, China) for collecting the material.

\section{References}

Carvalho, C. J. B. De, Couri, M. S., Pont, A. C., Pamplona, D. \& Lopes, S. M. 2002: A catalogue of the Muscidae (Diptera) of the Neotropical Region. - Zootaxa 860: $1-282$.

Fan, Z. D. 1993: Muscidae (II). — In: Chen, S. X. (ed.), Insects of the Hengduan Mountains Region. Volume 2. Science Press, Beijing. Pp. 1252-1270. [In Chinese.]

Hennig, W. 1955-1964. Family Muscidae. — In: Lindner, E. (ed.), Die Fliegen der Palaearktischen Region 63b: 1-1110. Schweizerbart, Stuttgart.

Huckett, H. C. 1965a: The Muscidae of Northern Canada, Alaska, \& Greenland (Diptera). - Memoirs of the Entomological Society of Canada 42: 1-369.

Huckett, H. C. 1965b: Family Muscidae. — In: Stone, A, Sabrosky, C. W., Wirth, W. W., Foote, R. H. \& Coulson, J. R. (eds.), A catalog of the Diptera of America north of Mexico. - United States Department of Agriculture, Agriculture Handbook 276: 869-915.

McAlpine, J. F. 1981: Morphology and terminologyadults. — In: McAlpine, J. F., Peterson, B. V., Shewell, 
G. E., Teskey, H. J., Vockeroth, J. R. \& Wood, D. M. (eds.), Manual of Nearctic Diptera. Volume 1. Agriculture Canada Monograph 27: 9-63.

Meigen, J. W. 1826: Systematische Beschreibung der bekannten europäischen zweiflügeligen Insekten. Volume 5. Hamm, Schultz. 412 pp. [In German]

Pont, A. C. 1977: Family Muscidae. — In: Delfinado, M. D. \& Hardy, D. E. (eds.), A catalog of the Diptera of the Oriental Region. University of Hawaii, Honolulu 3: 451-523.

Pont, A. C. 1980: Family Muscidae. - In: Crosskey, R. W. (ed.) Catalogue of the Diptera of the Afrotropical Region. British Museum (Natural History), London. Pp. 721-761.

Pont, A. C. 1981: Himalayan Muscidae. III. The genus Pogonomyia Rondani (Diptera). - Spixiana 4: 121-136.

Pont, A. C. 1986: Family Muscidae. — In: Soós, Á. \& Papp, L. (eds.), Catalogue of Palaearctic Diptera: 57215. Volume 11. Akadémiai Kiadó, Budapest.

Pont, A. C. 1989: Family Muscidae. — In: Evenhuis, N. L. (ed.), Catalog of the Diptera of the Australasian and Oceanian regions. Bishop Museum Special Publication 86: 675-699.

Shinonaga, S. \& Singh, M. M. 1994: Muscidae of Nepal (Diptera). I. Muscinae, Stomoxyinae and Phanonii- nae. - Japanese Journal of Sanitary Zoology 45 (Supp1.): $99-177$.

Xue, W. Q. \& Zhang, X. Z. 1996a: Muscidae. - In Wu, S. G. and Feng, Z. J. (eds.), The biology and human physiology in the Hoh Xil region. Science Press, Beijing: 199-201. [In Chinese.]

Xue, W. Q. \& Zhang, X. Z. 1996b: Insects of the Karakorum-Kunlun Mountains. Science Press, Beijing: 216218. [In Chinese.]

Xue, W. Q. \& Chao, C. M. (eds.), 1998: Flies of China. Volume I. [In Chinese.] Liaoning Science and Technology Press, Shenyang. Pp. 836-1365.

Xue, W. Q., Zhang, C. T., Wang M. F., Zhou, Z. K., Wu, J. W. \& Xiang, C.Q. 1992: Study on the genus Drymeia of China (Diptera: Muscidae). - A paper for the 19th international congress of Entomology, Shenyang Normal College: 1-16.

Xue, W. Q., Wang, D. D., Wang, M. F. \& Xhiang, C. Q. 2007: Five new species of Drymeia Meigen from Tibet Plateau, China (Diptera: Muscidae). - Zootaxa 1444: 35-51.

Zhong, Y. H., Wu, F. L. \& Fan, Z. D. 1981: Notes on Calypterate flies from Xizang district, China. - Contributions from Shanghai Institute of Entomology 2: 241248. [In Chinese.] 